\title{
ZJXG Decoction Promotes the Expression of Bone Morphogenetic Protein-7 to Enhance Fracture Healing In Rats
}

\author{
Yunliang Guo*, Xiangjie Wang, Yuexing Pan, Zhixian Du and Zhen Zhou
}

Affiliated Hospital, Qingdao University Medical College, China

\begin{abstract}
The aim is to investigate the effects of Zhuang Jin Xu Gu Decoction (ZJXG Decoction) on femoral fracture healing in rats. Femur fractures were generated in fifty male adult Wistar rats by cutting femur transversely at middle point. ZJXG Decoction was administered orally after surgery for 7-14 d. Radiological evaluation or X-ray imaging analysis indicated that the fibrous callus tissue at the femoral fracture-end increased and the fracture line became fuzzy at 7-14 d following treatment with ZJXG Decoction. Hematoxtlin-Eosin (HE) staining showed that the fibrous-granular tissue at the fracture-end changed gradually to fibrous, cartilaginous and osseous callus tissues. immunohistochemical staining and Enzyme Linked Immunobsorbent Assay (ELISA) results showed that BMP-7 in the fibroblasts and osteoblasts of callus and its serum level increased significantly 7-14 $\mathrm{d}$ following treatment with ZJXG Decoction. It is concluded that ZJXG Decoction could enhance the fracture healing by up-regulating the expression of BMP-7 in fibroblasts and osteoblasts of callus in rats.
\end{abstract}

Keywords: ZJXG decoction; Fracture; Callus; Pathology; Bmps; Rats

\section{Introduction}

The fracture healing is an extremely complicated process of skeletal reconstruction. Many growth factors could promote osteoblast development, proliferation, differentiation and accelerate new bone formation in the process of fracture healing and remodeling [1]. Bone Morphogenetic Proteins (BMPs) and Neuropeptide Y (NPY) play important roles in bone fracture repair process [2]. BMP induces cartilage and bone formation [3] and been used to treat fracture models in rodents [4-6], and some experimental and clinical reports illustrated the effect of BMP7 on fracture healing [7-9]. Current fracture care includes internal and external fixation with early mobilization to restore function earlier and more completely. But fracture fixation could cause serious trauma and mostly need the secondary operation. In addition, it increases the risk of infection and the rates of delayed union, and nonunion [10]. Traditional Chinese Medicine Zhuang Jin $\mathrm{Xu} \mathrm{Gu}$ Decoction (ZJXG Decoction) has been clinically used for promoting fracture healing for many years [11]. The exact therapeutic mechanism by which ZJXG Decoction enhances healing in rodent model, however, still remains unclear. Here we aimed to elucidate if the effects of ZJXG Decoction in fracture repair was related to the expression of BMP-7.

\section{Materials and Methods}

\section{Animal model and grouping}

Total of 50 male adult Wistar rats (Experiment Animal Center of Qingdao Drug Inspection Institute, SCXK (LU) 20090010) weighting 190-210 g were used and all experimental procedures were approved by the Ethics Committee of Qingdao University Medical College (No.QUMC2011-09) in this study. The rats were anesthetized with intraperitoneal injection of $100 \mathrm{~g} / \mathrm{L}$ chloral hydrate $(300 \mathrm{mg} / \mathrm{kg})$ and then restrained in a supine position for operation. The femoral fracture model was established by cutting the femur transversely at the middle section (about $1.0 \mathrm{~cm}$ below the great trochanter) from medial parapatellar incision [12]. After the manual reduction, the fractured femur was fixed with intramedullary Kirschner wires (diameter 1.0 mm, Shanghai Medical Apparatus Co. Ltd.). The sham group was subjected to the same procedure except without cutting femur. Animals were allowed to drink and eat freely after surgery. The survival rate is $100 \%$. The rats were divided randomly into five groups of 10 rats in each group. The low, medium and high dose group rats were treated with ZJXG Decoction of $1.25,2.5$ and $5 \mathrm{~g} / \mathrm{kg}$ respectively while the vehicle was given at the same volume to sham and control group rats. At the time points of $7 \mathrm{~d}$ or $14 \mathrm{~d}$, rats were subjected to X-ray image taking after chloral hydrate anesthesia and then euthanized for blood and tissue collection.

\section{Preparation of ZJXG decoction}

Zhuang Jin Xu Gu Decoction (ZJXG Decoction) was derived from the ZJXG Pellet recorded in "Shang Ke Da Cheng" written by Zhao Lian of the Qing Dynasty in China. It is composed of 12 constituents listed in table 1. The ZJXG Decoction was decocted according to the Standard of Decocting Herbal Medicine promulgated by Chinese Administration Department of Traditional Chinese Medicine. The mixture of all herbal plants were immersed in distilled water for $20-30 \mathrm{~min}$ at $20-25^{\circ} \mathrm{C}$ with relative humidity $\leq 85 \%$, and then cooked to the boil, kept on simmer for 10-15 min to concentrate the extracts, protecting and maintaining all essential ingredients. The same procedure was repeated for 2 times. The two extractions yielded an amount of $224 \mathrm{ml}$ liquid medicinal decoction containing $112 \mathrm{~g}$ of dry weight (concentration of $0.5 \mathrm{~g} / \mathrm{ml}$ ) which was packed with sterilized plastic bags and stored at $-20^{\circ} \mathrm{C}$.

\section{Radiological and gross observation}

An initial X-ray examination was performed in all animals after the fracture. At 7 and $14 \mathrm{~d}$ following surgery, all the rats were anesthetized for X-ray evaluation (GE Revolution RE/d, USA). The anesthetized rats were then sacrificed and the femurs were taken out, washed normal saline for general observation.

*Corresponding author: Yunliang Guo, Affiliated Hospital, Qingdao University Medical College, China, Tel: 86-0532-82911523; Fax: 86-0532-82911840; E-mail: mailto:guoqdsd@yahoo.com.cn

Received July 16, 2012; Accepted August 01, 2012; Published August 03, 2012

Citation: Guo Y, Wang X, Pan Y, Du Z, Zhou Z (2012) ZJXG Decoction Promotes the Expression of Bone Morphogenetic Protein-7 to Enhance Fracture Healing In Rats. J Trauma Treat 1:142. doi:10.4172/2167-1222.1000142

Copyright: (c) 2012 Guo Y, et al. This is an open-access article distributed unde the terms of the Creative Commons Attribution License, which permits unrestricted use, distribution, and reproduction in any medium, provided the original author and source are credited. 


\begin{tabular}{|l|l|l|c|}
\hline Sources & English Name & Latin Name & Dose \\
\hline Gansu & Chinese Angelica & Radix Angelicae Sinensis & $12 \mathrm{~g}$ \\
\hline Sichuan & Rhizoma Chuanxiong & Rhizoma Chuanxiong t & $12 \mathrm{~g}$ \\
\hline Henan & $\begin{array}{l}\text { Radix Rehmanniae } \\
\text { Preparata }\end{array}$ & Radix Rehmanniae Preparata & $10 \mathrm{~g}$ \\
\hline Inn Mongulia & Milkvetch Root & Radix Astragali & $12 \mathrm{~g}$ \\
\hline Sichuan & Eucommia Bark & Eucommia ulmoides Oliv & $12 \mathrm{~g}$ \\
\hline Schuan & Himalayan Teasel Root & Radix Dipsaci Asperoidis & $12 \mathrm{~g}$ \\
\hline Guangxi & $\begin{array}{l}\text { Fortune's Drynaria } \\
\text { Rhizome }\end{array}$ & Rhizoma Drynariae & $12 \mathrm{~g}$ \\
\hline Yunnan & Sanchi & Radix Notoginseng & $10 \mathrm{~g}$ \\
\hline Inn Mongulia & White Paeony Root & Radix Paeoniae Alba & $10 \mathrm{~g}$ \\
\hline Xinjiang & Safflower & Flos Carthami & $10 \mathrm{~g}$ \\
\hline Total & & & $112 \mathrm{~g}$ \\
\hline
\end{tabular}

Table 1: Chinese herbal medicines of ZJXG Decoction.

\section{Histological analysis}

For morphological analysis, the femur were cut and incubated in 40 $\mathrm{g} / \mathrm{L}$ formaldehyde solution for $4 \mathrm{~h}$ and rinsed in distilled water for $4 \mathrm{~h}$, and then decalcificated for 10 days in $20 \%$ Ethylenediamine Tetraacetic Acid (EDTA). The samples were then dehydrated using graded ethanol, immersed in dimethylbenzene for $2 \mathrm{~h}$, embedded by paraffin. The 7 $\mu \mathrm{m}$ thickness slices were made by mirotome (Leica RM2015, Shanghai Leica Instruments, China) and attached to poly-L-lysine processed slides. Paraffin sections were deparaffinaged in dimethylbenzene, hydrated in gradient ethanol and rinsed with distilled water. The sections were stained with Hematoxylin-Eosin (HE).

\section{Immunohistochemical staining}

For immunostaing, antigen retrieval was made using a microwave oven. The sections were incubated with rabbit anti rat BMP-7 polyclonal antibodies at $4^{\circ} \mathrm{C}$ overnight. Negative control used PBS instead of primary antibodies. Immunohistochemical procedures were performed strictly according to the SABC kit manual. Four serial sections from each experimental rat were observed under a light microscope (manufacture). LEICA Qwin microgramme analytical system was used to analyze the expression of immunosignals, illustrated by absorbance values (A).

\section{Enzyme linked immunobsorbent assay (ELISA)}

About $4 \mathrm{ml}$ blood was aseptically collected from abdominal aorta of each rat and centrifugalized for 10 minutes at $4000 \mathrm{r} / \mathrm{min}$ at $4^{\circ} \mathrm{C}$ to separate the serum which was then kept at $-20^{\circ} \mathrm{C}$ until required for analysis. The serum level of BMP-7 measured using commercially available ELISA kits (Blue Gene Co. Ltd). The procedure was performed following manufacturer's instruction. The OD was calculated with BioRad 550 microplate reader (USA) set to $450 \mathrm{~nm}$ to reflect the level of BMP-7. The assay sensitivity is $1.0 \mathrm{ng} / \mathrm{L}$.

\section{Statistical analysis}

The data was expressed by mean \pm standard deviation $(\bar{x} \pm s)$ and analyzed with SPSS 11.5 statistical software. Analysis of variance was used to compare whether there are obvious differences among groups. $P<0.05$ was considered significantly.

\section{Results}

\section{$\mathrm{X}$-Rays and gross observation}

$\mathrm{X}$-rays revealed that the fracture-end of femur of the control group began forming fibrous callus at 7 day after surgery with the fracture line still clear; at 14 days, the fracture line became unclear. In the treated groups, the fibrous callus was more than that in the control group and the fracture line became fuzzy at 7 days and tended to disappear at 14 days following treatment. On day 7 in control group, granulation tissue in the fracture breaking-end was observed and fibrous callus at 14 days following surgery. In the treated groups, fibrous callus formed at 7 days and formation of cartilaginous and osseous callus was present on day 14 (Figure 1). There was no statistical difference among treatment groups.

\section{HE staining}

On day 7 , in control group, the inflammatory cell infiltration, formation of granulation tissues occurred between fracture fragments. The proliferation of fibroblast and osteoblasts under periosteum was localized in the fracture gap. On day 14 of control rats, the number of fibroblasts and osteoblasts increased and fibrous callus had formed with a small cartilaginous callus. In the treated groups, the inflammatory cells decreased and the fibroblasts and osteoblasts increased in the fractured bone end 7 days after treatment compared to control, while on day 14 a lot of fibrous, cartilaginous and osseous callus tissues had developed and newly formed bone trabeculae appeared (Figure 2).

\section{Immunohistochemistry}

Minimal expression of BMP-7 was detected in the sham group ( $P$ $>0.05$ ). BMP-7 positive cells were observed in callus tissues in control group on day 7 and the absorbance values on day 14 was greater compared to $7 \mathrm{~d}$ control group $(P<0.05)$. In paired comparisons of groups, the grade of values of absorbance $(A)$ of BMP-7 was significantly higher in the treatment groups compared to control group $(P<0.05)$. It was not significantly different among the high-dose, medium-dose and low-dose treated groups $(P>0.05)$ (Table 2 and Figure 3$)$.

\section{The serum levels of BMP-7}

There was no significant difference of serum level of BMP-7

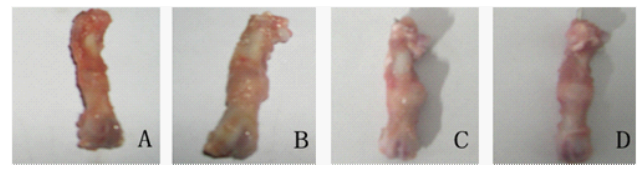

Figure 1: Gross Observation of Tissue Samples on Day 7 in Control Group (A) Day 7 in Low-Dose Treated Group (B); Day 14 in Control Group (C) and Day 14 in Low-Dose Treated Group (D).
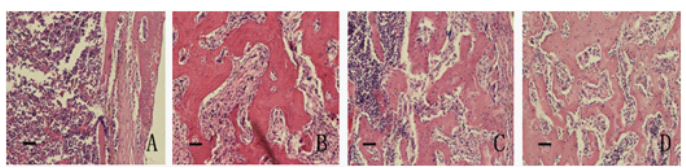

Figure 2: Hematoxylin and Eosin Staining on Tissues Collected On Day 7 in Control Group (A) and Treatment Group (B), on Day 14 in Control Group (C) and Treatment Group (D). Scale Bar $=50 \mu \mathrm{m}$.

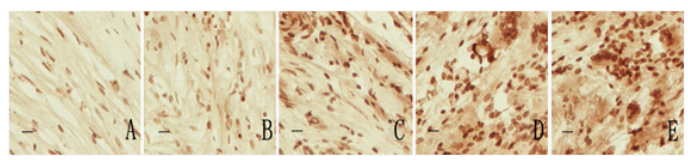

Figure 3: The Expression of BMP-7, DAB $\times 200$, Scale Bar $=25 \mu \mathrm{m}$. A: Sham Group, B: 7 Days in Control Group, C: 7 Days in Low-Dose Group, D: 14 Days in Control Group, E: 14 Days in Low-Dose Group. 
Citation: Guo Y, Wang X, Pan Y, Du Z, Zhou Z (2012) ZJXG Decoction Promotes the Expression of Bone Morphogenetic Protein-7 to Enhance Fracture Healing In Rats. J Trauma Treat 1:142. doi:10.4172/2167-1222.1000142

\begin{tabular}{|c|c|c|c|c|c|}
\hline \multirow[b]{2}{*}{ Groups } & \multirow[b]{2}{*}{ Dose } & \multicolumn{2}{|c|}{ Absorbance $(A)$} & \multicolumn{2}{|c|}{ concentration (ng/L) } \\
\hline & & $7 d$ & $14 \mathrm{~d}$ & $7 d$ & $14 \mathrm{~d}$ \\
\hline Sham group & NS & $0.24 \pm 0.07$ & $0.25 \pm 0.06$ & $112.24 \pm 10.71$ & $115.50 \pm 12.20$ \\
\hline Control group & NS & $0.28 \pm 0.06^{a}$ & $0.43 \pm 0.08^{a c}$ & $386.28 \pm 41.04^{a}$ & $430.37 \pm 45.00^{\mathrm{ac}}$ \\
\hline Low-dose group & $1.25 \mathrm{~g} / \mathrm{kg}$ & $0.65 \pm 0.12^{\mathrm{b}}$ & $0.71 \pm 0.14^{b c}$ & $679.15 \pm 64.62^{b}$ & $783.15 \pm 73.41^{\mathrm{bc}}$ \\
\hline Medium-dose group & $2.5 \mathrm{~g} / \mathrm{kg}$ & $0.62 \pm 0.12^{\mathrm{b}}$ & $0.81 \pm 0.12^{b c}$ & $722.15 \pm 70.12^{b}$ & $861.56 \pm 75.12^{b c}$ \\
\hline High-dose group & $5.0 \mathrm{~g} / \mathrm{kg}$ & $0.63 \pm 0.13^{b}$ & $0.83 \pm 0.15^{b c}$ & $730.24 \pm 75.00^{b}$ & $853.35 \pm 81.05^{\mathrm{bc}}$ \\
\hline
\end{tabular}

a $\mathrm{P}<0.05$ vs sham group, b $\mathrm{P}<0.05$ vs control group, $\mathrm{c} P<0.05$ vs treated $7 \mathrm{~d}$

Table 2: The expression values of absorbance $(A)$ and serum concentration of $B M P-7(X \pm S, n=5)$.

between day 7 and day 14 in sham operation group $(P>0.05)$. It is significantly different between day 7 and day 14 within other each group, with higher levels on day $14(P<0.05)$. At same time points, the serum level of BMP-7 in the control group was significantly higher than those in sham operation group and significantly lower than those in the treated groups $(P<0.05)$. No significant difference among the high-dose, medium-dose and low-dose groups was observed $(P>0.05)$ (Table 2).

\section{Discussion}

Previous clinical studies have demonstrated that applications of ZJXG Decoction enhanced healing of fractured humerus and femur [13-15]. Consistent with these empirical observations, here we presented the first robust evidence of the effectiveness of ZJXG Decoction in the promotion of fracture healing in the experimental animal. Fracture healing is an extremely complex process which is reportedly influenced by multiple cytokines and growth factors [16]. In the present study, we hypothesized that the efficacy of ZJXG Decoction be mediated via the up-regulation of local and systematic BMP-7. Bone Morphogenetic Proteins (BMPs) are known to play critical roles in the formation of cartilage and bone during embryonic development, and the loss of certain BMP molecules leads to a severe impairment of osteogenesis [17]. The molecules of BMP-2, -4, -5, -6, -7, and -9 have effects on osteogenic action [18], though different members play specific roles in bone formation during different stages. BMP-7 induces osteogenic differentiation of mesenchymal stem cells by regulating the transcription factors Runx2 and Osterix [19].

In addition to the effects in skeletal development, BMP-7 has been well characterized for its involvement in the fracture healing. For example, Kloen et al. [20] showed $t$ the presence of BMP molecules including BMP-7 in human fracture callus. In another study, clinical application of BMP-7 could induce the osteoblastic activity and repair bony defects [21]. Furthemore, rhBMP-7 accelerated the healing in distal tibial fractures treated by external fixation [22]. The results of these studies suggest BMP-7 can be a positive modulator of fracture healing. This experiment showed that the BMP-7 expression in blood and in the femoral fracture callus tissue of rats significantly increased after treatment with ZJXG Decoction at different stages; meanwhile, HE staining and X-ray evaluation demonstrated the efficacy of ZJXG Decoction in enhancing the fracture healing. The current data suggested the involvement of BMP-7 be an important mediator in the accelerated healing by ZJXG Decoction. Other Chinese herbal medicines such as Mixture of Kidney-Tonifying also increased BMPs concentration in the area of implant-synostosis and promoted fracture healing of rats. It is therefore possible that up-regulation of MBP-7 could be a common therapeutic mechanism employed by different treatments for enhancing fracture healing.

\section{Conclusions}

The current data demonstrated that ZJXG Decoction significantly promotes the fracture healing in a fracture rat model, and might partially be due to its influence on the expression of growth factors of BMP-7. Future studies will be needed to investigate which signaling pathways are affected by ZJXG decoction.

\section{Acknowledgements}

This study was supported by grant-in-aids for the Best Article Culture Fund for Graduate of Qingdao University (No. YSPY2011012).

\section{References}

1. Pogoda P, Priemel M, Rueger JM, Amling M (2005) Bone remodeling: new aspects of a key process that controls skeletal maintenance and repair. Osteoporos Int 16: 18-24.

2. Oreffo RO (2004) Growth factors for skeletal reconstruction and fracture repair Curr Opin Investig Drugs 5: 419-423.

3. Chen X, Kidder LS, Lew WD (2002) Osteogenic protein-1 induced bone formation in an infected segmental defect in the rat femur. J Orthop Res 20 142-150.

4. David J, Takeshi Makino, Takahiro Niikura, Scott J, Shane Curtiss, et al. (2006) Recombinant human BMP-7 effectively prevents nonunion in both young and old rats. J Orthop Res 24: 11-20.

5. Lu CY, Xing Z, Yu YY, Colnot C, Miclau T, et al. (2010) Marcucio Recombinant Human Bone Morphogenetic Protein-7 Enhances Fracture Healing in an Ischemic Environment. J Orthop Res 28:687-696.

6. den Boer FC, Bramer JA, Blokhuis TJ, Van Soest EJ, Jenner JM, et al. (2002) Effect of recombinant human osteogenic protein-1 on the healing of a freshly closed diaphyseal fracture. Bone 31:158-164.

7. Blattert TR, Delling G, Dalal PS, Toth CA, Balling H, et al. (2002) Successfu transpedicular lumbar interbody fusion by means of a composite of osteogenic protein-1 (rhBMP-7) and hydroxyapatite carrier: a comparison with autograft and hydroxyapatite in the sheep spine. Spine 27: 2697-2705.

8. Andrew P, Alexander R, Jeremy A, Peter G, Brian C, et al. (2007) Clinical applications of BMP-7/OP-1 in fractures, nonunions and spinal fusion. Int Orthop 31: 735-741

9. Liu WL, Wang KQ, Jiao XL, Gao ZB (2009) Effects of bone morphogenetic protein 7 in articular cartilage on the pathology course of osteoarthritis. The Journal of Traditional Chinese Orthopedics and Traumatology 21: 17-19.

10. Zhao ZC, Cao ZQ, Li H, Wang DW (2011) Progress of Traditional Chinese Medicine on the fracture healing. Shaanxi Journal of Traditional Chinese Medicine 32: 636-637.

11. Li K, Shi M, Li WH (2009) Experimental study of Traditional Chinese Medicine on postoperative healing of fracture. Journal of Liaoning University of Traditional Chinese Medicine 11: 69-71.

12. Wang X, Song YM, Pei FX (2005) The effects of central nervous system injury on femur fracture healing of rats. Chin J Orthop Surg 13: 1570-1572.

13. Kuang JH, Kuang JHo, Luo XH, Kuang JJ, et al. (2003) Shang Decoction promoting fracture healing of 50 cases. Hunan Journal of Traditional Chinese Medicine 19: 19-20.

14. Zhang XH, Guo XQ, Zeng SC, Xiao F, Chen SM, et al. (2006) The humera fracture nonunion of 43 cases treated by unilateral function external fixation combing Traditional Chinese herbal medicines. Jiangxi Journal of Traditional Chinese Medicine 37: 37-38.

15. Li JB, Zhang JH (2010) Therapeutic effect of Jie Gu syrup on fracture of rib and its clinical research. Hubei Journal of Traditional Chinese Medicine 32: 26-27. 
Citation: Guo Y, Wang X, Pan Y, Du Z, Zhou Z (2012) ZJXG Decoction Promotes the Expression of Bone Morphogenetic Protein-7 to Enhance Fracture Healing In Rats. J Trauma Treat 1:142. doi:10.4172/2167-1222.1000142

16. Westerhuis RJ, van Bezooijen RL, Kloen P (2005) Use of bone morphogenetic proteins in traumatology. Injury 36: 1405-1412.

17. Bandyopadhyay A, Tsuji K, Cox K., Harfe BD, Rosen V, et al. (2006) Genetic analysis of the roles of $\mathrm{BMP}_{2}, \mathrm{BMP}_{4}$, and $\mathrm{BMP}_{7}$ in limb patterning and skeletogenesis. PLoS Genet 2: e216.

18. Xiao YT, Xiang LX, Shao JZ (2007) Bone morphogenetic protein. Biochem Biophys Res Commun 362: 550-553.

19. Komaki1 M, Asakura A, Rudnicki MA, Sodek J, Cheifetz S (2004) Myo D enhances BMP7-induced osteogenic differentiation of myogenic cell cultures. J Cell Sci 117: 1457-1468
20. Kloen P, Di Paola M, Borens O, Richmond J, Perino G, et al. (2003) BMP signaling components are expressed in human fracture callus. Bone 33: 362 371.

21. Geesink RG, Hoefnagels NH, Bulstra SK (1999) Osteogenic activity of OP-1 bone morphogenetic protein (BMP-7) in a human fibular defect. J Bone Joint Surg $\mathrm{Br}$ 81: 710-718.

22. Ristiniemi J, Flinkkilä T, Hyvönen $P$, Lakovaara M, Pakarinen H, et al. (2007) RhBMP-7 accelerates the healing in distal tibial fractures treated by externa fixation. J Bone Joint Surg Br 89: 265-272. 